\title{
HIPK2-T566 autophosphorylation diversely contributes to UV- and doxorubicin-induced HIPK2 activation
}

\author{
Alessandra Verdina ${ }^{1, *}$, Giuliana Di Rocco ${ }^{1, *}$, Ilaria Virdia ${ }^{1}$, Laura Monteonofrio ${ }^{1}$, \\ Veronica Gatti ${ }^{1,4}$, Eleonora Policicchio², Alessandro Bruselles ${ }^{2}$, Marco Tartaglia ${ }^{3}$, \\ Silvia Soddu ${ }^{1}$ \\ ${ }^{1}$ Unit of Cellular Networks and Molecular Therapeutic Targets, Department of Research, Advanced Diagnostics, and \\ Technological Innovation, Regina Elena National Cancer Institute - IRCCS, Rome, Italy \\ ${ }^{2}$ Department of Hematology, Oncology and Molecular Medicine, Istituto Superiore di Sanità, Rome, Italy \\ ${ }^{3}$ Genetics and Rare Diseases Research Division, Ospedale Pediatrico Bambino Gesù - IRCCS, Rome, Italy \\ ${ }^{4}$ Present address: Istituto di Biologia Cellulare e Neurobiologia, CNR, Monterotondo Scalo, Rome, Italy \\ * These authors have contributed equally to this work \\ Correspondence to: Silvia Soddu, email: silvia.soddu@ifo.gov.it \\ Keywords: HIPK2, phosphorylation, DNA-damage response, cancer stem cells \\ Received: October 04, $2016 \quad$ Accepted: December 15, $2016 \quad$ Published: January 02, 2017
}

\section{ABSTRACT}

HIPK2 is a Y-regulated S/T kinase involved in various cellular processes, including cell-fate decision during development and DNA damage response. Cisautophosphorylation in the activation-loop and trans-autophosphorylation at several S/T sites along the protein are required for HIPK2 activation, subcellular localization, and subsequent posttranslational modifications. The specific function of a few of these autophosphorylations has been recently clarified; however, most of the sites found phosphorylated by mass spectrometry in human and/or mouse HIPK2 are still uncharacterized. In the process of studying HIPK2 in human colorectal cancers, we identified a mutation (T566P) in a site we previously found autophosphorylated in mouse Hipk2. Biochemical and functional characterization of this site showed that compared to wild type (wt) HIPK2, HIPK2-T566P maintains nuclear-speckle localization and has only a mild reduction in kinase and growth arresting activities upon overexpression. Next, we assessed cell response following UV-irradiation or treatment with doxorubicin, two well-known HIPK2 activators, by evaluating cell number and viability, p53-Ser46 phosphorylation, p21 induction, and caspase cleavage. Interestingly, cells expressing HIPK2-T566P mutant did not respond to UV-irradiation, while behaved similarly to wt HIPK2 upon doxorubicin-treatment. Evaluation of HIPK2-T566 phosphorylation status by a T566-phospho-specific antibody showed constitutive phosphorylation in unstressed cells, which was maintained after doxorubicin-treatment but inhibited by UV-irradiation. Taken together, these data show that HIPK2-T566 phosphorylation contributes to UV-induced HIPK2 activity but it is dispensable for doxorubicin response.

\section{INTRODUCTION}

HIPK2 (Homeodomain-Interacting Protein Kinase 2) is an evolutionarily conserved tyrosine-regulated serine/threonine kinase. HIPK2 phosphorylates a large body of proteins belonging to different signaling pathways involved in the control of development, cell response to DNA damage and hypoxia, differentiation, and cytokinesis [reviewed in 1-4].
In physiological conditions, HIPK2 localizes mainly in nuclear speckles, including PML-bodies, and only a small fraction is found in the nucleoplasm or cytosol [5]. In unstressed cells, HIPK2 is constantly degraded by the ubiquitin-proteasome system [6]. In stressing conditions, such as in response to UV, ionizing radiation, and chemotherapeutic drugs, HIPK2 stability is regulated by different ubiquitin E3 ligases [6-10] and induces cell cycle arrest or apoptosis through p53- 
dependent and -independent mechanisms [11-15]. In addition to ubiquitylation, HIPK2 is regulated by different posttranslational modifications (PTMs), caspase cleavage [16], and by the interaction with scaffold proteins $[9,17]$. Of relevance, HIPK2 PTMs have been shown to occur in a hierarchical fashion, with phosphorylation being required for sumoylation, and the latter controlling acetylation $[4,18]$.

Thus far, different RefSeqs have been used for HIPK2 aminoacid numbering. Here, we will refer to the current NCBI RefSeq (i.e., NP_073577.3 and NP_034563.2 for human and mouse HIPK2, respectively) and, when required, add in brackets the aminoacid number used in the relative references. Both human and mouse HIPK2 have been shown to become catalytically active by their cis-autophosphorylation of the activation loop at Y361 (Y354) and S364 (S357) [19-21]. Of relevance, the cis-autophosphorylation also controls the subcellular localization of HIPK2 and its substrate affinity [1921]. Subsequent HIPK 2 phosphorylations take place at multiple sites ( $>40$ sites pooling current mouse and human data) distributed throughout the different HIPK2 domains both by trans-autophosphorylation at $\mathrm{S} / \mathrm{T}$ sites and phosphorylation by other, mostly unknown kinases, in $\mathrm{S} / \mathrm{T}$ and $\mathrm{Y}$ sites (Table 1). The functional consequences of a few of these phosphorylations are becoming clear. For example, in DNA damage response (DDR), HIPK2 activation and accumulation is induced by its autophosphorylation at $\mathrm{T} 880 / \mathrm{S} 882$ that creates a binding signal for the phospho-specific isomerase Pin1 [22], or by c-Abl-mediated phosphorylation at Y367 (Y360) [23]. An inhibitory phosphorylation of HIPK2 by AMPK $\alpha 2$ at T119 (T112), S121 (S114), and T1114 (T1107) has been shown to release WIP1, a homeostatic regulator of DDR, from the HIPK2-mediated phosphorylation and degradation [24]. More recently, HIPK2 phosphorylation at S359/ T360 in the activation loop has been causally linked to ER stress-mediated neurodegeneration in amyotrophic lateral sclerosis [25]. In contrast, substitutions of the putative S/T phosphorylation sites at position S118 (S111), S121 (S114), S441 (S434), T450 (T443), and T517 (T510) with non-phosphorylatable alanine did not reduce HIPK2 kinase activity in in vitro assays [19].

HIPK2 dysregulation has been shown to contribute to proliferative diseases, such as cancer and tissue fibrosis [2, 26-28]. Based on our current knowledge, three possible mechanisms explaining the functional inactivation of HIPK2 have been proposed: the "localization model", the "optimum model", and the "PTM model" which foresee, respectively, tight regulations of HIPK2 subcellular localization, protein levels, and PTMs [18]. Mutations in the HIPK2 gene are sporadic in human cancers (Catalogue of somatic mutations in cancer - COSMIC http://cancer. sanger.ac.uk/cosmic) and their contribution to HIPK2 dysregulation has only been rarely verified [29]. By wholeexome sequencing of patient-derived colorectal cancer stem cells (C-CSCs), we identified a mutation (T566P) in one of the sites we previously found autophosphorylated in mouse Hipk2 (T599 in ref. 20) (Table 1) [20]. Here, we investigated the contribution of this site in the HIPK2 activity. We observed an impairment of UV-induced HIPK2 reaction while the HIPK2-mediated response to doxorubicin was not affected, indicating the existence of a DDR-specific phospho-mediated regulation of this kinase.

\section{RESULTS AND DISCUSSION}

In the frame of an effort directed to profile and functionally characterize the cancer driving events affecting a panel of C-CSCs obtained by selective culture from colorectal tumor specimens [30], whole-exome sequencing was carried out using genomic DNA from $24 \mathrm{C}-\mathrm{CSC}$ lines and patient-matched non-tumor tissues. Statistics and data output is reported in Supplementary Table 1. Among the multiple hits identified, two different somatically acquired missense changes, c.1694A $>C$ (p.Lys565Thr, K565T hereafter) (line CTSC85) and c.1696A $>$ C (p.Thr566Pro, T566P hereafter) (line CTSC47) (Supplementary Figure 1A), affecting HIPK2 were identified. Both residues were almost invariably conserved among vertebrates and were located in a highly conserved amino acid stretch (Supplementary Figure 1B), strongly suggesting a possible functional impact of both changes. Consistently, both substitutions were predicted to be damaging by Combined Annotation Dependent Depletion prediction tool [31]. Of note, H565 had previously shown to be an ubiquitylation site and its substitution had been shown to reduce Siah1-mediated degradation in the absence of any appreciable effect on the catalytic activity of the kinase [6]. On the other hand, T566 was previously recognized as one of the sites undergoing reversible autophosphorylation in mouse Hipk2, which suggested a possible role of T566 phosphorylation in the control/modulation of HIPK2 function, and a direct impact of the T566P change on perturbing HIPK2 activity by affecting phosphorylation at T566.

To evaluate whether the T566P amino acid substitution is relevant for HIPK2 localization and activity, we first introduced the T566P mutation in an EGFP-tagged wt HIPK2-expressing vector. Mutation of the nearby K565 to T, found in C-CSC from a different patient (Supplementary Figure 1A), was engineered as control. Transfection of these three vectors (WT, T566P, and $\mathrm{K} 565 \mathrm{~T}$ ) was performed by electroporation in wt $\mathrm{p} 53$ carrying U2OS cells. Mock transfected cells (MOCK) and cells transfected with the EGFP empty vector (GFP) were used as control.

HIPK2 mainly localizes into nuclear speckles and specific PTMs, such as cis-autophosphorylation, sumoylation, and acetylation can regulate the localization of the kinase. Thus, we first evaluated the localization of our GFP-HIPK2 derivatives. As shown 
Table 1: Human and mouse HIPK2 phosphorylation sites

\begin{tabular}{|c|c|c|c|c|}
\hline Site* & Human HIPK2 & $\begin{array}{l}\text { Mouse } \\
\text { Hipk2 }\end{array}$ & Kinase & References \\
\hline $\mathrm{S} 16$ & & $\mathbf{x}$ & Auto $^{(\mathrm{P})}$ & {$[20]$} \\
\hline Y44 & $\mathbf{x}$ & & Src-overexpressing cells & {$[49]$} \\
\hline S118 & $\mathbf{x}$ & $\mathbf{x}$ & Auto $^{(\mathrm{P})}$ & {$[19,20]$} \\
\hline $\mathrm{T} 119$ & $\mathbf{x}$ & & AMPK $\alpha 2$ & {$[24]$} \\
\hline $\mathrm{S} 121$ & $\mathbf{x}$ & & AMPK $\alpha 2$ & {$[24]$} \\
\hline $\mathrm{S} 135$ & & $\mathbf{x}$ & n.d. & {$[20]$} \\
\hline T141 & & $\mathbf{x}$ & n.d. & {$[20]$} \\
\hline $\mathrm{T} 252$ & & $\mathbf{x}$ & n.d. & {$[20]$} \\
\hline Y258 & $\mathbf{x}$ & & Src-overexpressing cells & [49] \\
\hline Y264 & $\mathbf{x}$ & & Src-overexpressing cells & {$[49]$} \\
\hline $\mathrm{T} 273$ & & $\mathbf{x}$ & Auto $^{(\mathrm{P})}$ & {$[20]$} \\
\hline S359 & $\mathbf{x}$ & & ER-stress in ALS & {$[25,50,51]$} \\
\hline T360 & $\mathbf{x}$ & $\mathbf{x}$ & ER-stress in ALS & {$[23,25,52,53]$} \\
\hline Y361 & $\mathbf{x}$ & $\mathbf{x}$ & $c i s-$ Auto $^{(\mathrm{P})}$ & {$[19,20,54,55]$} \\
\hline S364 & $\mathbf{x}$ & $\mathbf{x}$ & cis-Auto $^{(\mathrm{P})}$ & {$[19,50,51,56,57,58,59]$} \\
\hline Y367 & $\mathbf{x}$ & & $\mathrm{c}-\mathrm{Abl}$ & {$[23]$} \\
\hline Y423 & $\mathbf{x}$ & & Src-overexpressing cells & [49] \\
\hline S441 & $\mathbf{x}$ & $\mathbf{x}$ & Auto $^{(\mathrm{P})}$ & {$[19,20]$} \\
\hline Y443 & $\mathbf{x}$ & & Src-overexpressing cells & [49] \\
\hline $\mathrm{T} 482$ & & $\mathbf{x}$ & n.d. & {$[20]$} \\
\hline T517 & $\mathbf{x}$ & $\mathbf{x}$ & n.d. & {$[19,20]$} \\
\hline Y558 & $\mathbf{x}$ & & Src-overexpressing cells & {$[49]$} \\
\hline T566 & $\mathbf{x} * *$ & $\mathbf{x}$ & Auto $^{(\mathrm{P})}$ & {$[20]$} \\
\hline S634 & & $\mathbf{x}$ & n.d. & {$[20]$} \\
\hline S668 & $\mathbf{x}$ & $\mathbf{x}$ & Auto $^{(\mathrm{P})}$ & {$[19,20,22]$} \\
\hline T687 & & $\mathbf{x}$ & n.d. & {$[20]$} \\
\hline S815 & & $\mathbf{x}$ & n.d. & {$[20]$} \\
\hline $\mathrm{S} 826$ & $\mathbf{x}$ & & & {$[19]$} \\
\hline S827 & $\mathbf{x}$ & $\mathbf{x}$ & Auto $^{(\mathrm{P})}$ & {$[19,20,22,59,60,61,62]$} \\
\hline T838 & $\mathbf{x}$ & & Auto $^{(\mathrm{P})}$ & {$[19,22,62]$} \\
\hline $\mathrm{S} 848$ & $\mathbf{x}$ & $\mathbf{x}$ & Auto $^{(\mathrm{P})}$ & {$[19,20,22]$} \\
\hline $\mathrm{T} 880$ & $\mathbf{x}$ & & Auto $^{(\mathrm{P})}$ & {$[22]$} \\
\hline $\mathrm{S} 882$ & $\mathbf{x}$ & & Auto $^{(\mathrm{P})}$ & {$[22]$} \\
\hline S924 & $\mathbf{x}$ & & Auto $^{(\mathrm{P})}$ & {$[22]$} \\
\hline T933 & $\mathbf{x}$ & & Auto $^{(\mathrm{P})}$ & {$[19]$} \\
\hline S934 & $\mathbf{x}$ & $\mathbf{x}$ & Auto $^{(\mathrm{P})}$ & {$[20,22]$} \\
\hline & & & & (Continued) \\
\hline
\end{tabular}




\begin{tabular}{|c|c|c|c|c|}
\hline Site* & Human HIPK2 & $\begin{array}{l}\text { Mouse } \\
\text { Hipk2 }\end{array}$ & Kinase & References \\
\hline S955 & $\mathbf{x}$ & & Auto $^{(\mathrm{P})}$ & [19] \\
\hline S977 & $\mathbf{x}$ & & Auto $^{(\mathrm{P})}$ & [19] \\
\hline S991 & & $\mathbf{x}$ & Auto $^{(\mathrm{P})}$ & {$[20]$} \\
\hline S993 & & $\mathbf{x}$ & Auto $^{(\mathrm{P})}$ & [20] \\
\hline S1014 & $\mathbf{x}$ & & Auto $^{(\mathrm{P})}$ & [19] \\
\hline S1042 & & $\mathbf{x}$ & Auto $^{(\mathrm{P})}$ & [20] \\
\hline $\mathrm{T} 1114$ & $\mathbf{x}$ & & AMPK $\alpha 2$ & [24] \\
\hline Y1136 & $\mathbf{x}$ & & Src-overexpressing cells & {$[38]$} \\
\hline S1153 & & $\mathbf{x}$ & Auto $^{(\mathrm{P})}$ & [20] \\
\hline S1186 & & $\mathbf{x}$ & Auto $^{(\mathrm{P})}$ & [20] \\
\hline Y1197 & $\mathbf{x}$ & & Src-overexpressing cells & {$[38]$} \\
\hline
\end{tabular}

*The current NCBI RefSeq, NP_073577.3 for human HIPK2 and NP_034563.2 for mouse Hipk2 proteins have been used. **This manuscript.

in Figure 1A, T566P mutant has a nuclear-speckled localization comparable to that of wt HIPK2 and HIPK2K565T mutant, whereas the GFP control showed a diffuse nuclear/cytoplasmic localization, as expected.

Next, we evaluated the kinase activity of the three GFP-HIPK2 derivatives on the kinase its-self, a non-specific substrate, the myelin basic protein (MBP), and two specific substrates, p53 and p63, as previously described [20]. GFP-HIPK2 derivatives overexpressed in U2OS cells were immunopurified and comparable protein amounts employed for in vitro kinase assays. Compared to wt HIPK2 and the ubiquitylation mutant, HIPK2-T566P mutant showed a very mild reduction of kinase activity on its-self and on MBP, while no significant difference was observed in the levels of p53 and p63 phosphorylation (Figure 1B).

HIPK2-mediated cell cycle arrest and apoptosis requires its kinase activity [11-13]. To verify whether the mild and partial reduction of the HIPK2-T566P kinase activity might be relevant for its function, we compared the survival and proliferation-suppressing activities of the three GFP-HIPK2 derivatives by EdU (5-ethynyl-2'deoxyuridine) incorporation upon expression in U2OS cells. A comparable, early and mild induction of cell death was observed among the cell populations transduced with the three EGFP-HIPK2 derivatives $(4 \pm 0.5 \%, 6 \pm 0.6 \%$, and $9 \pm 0.8 \%$ for WT, T566P, and K565T, respectively). Single-cell analyses for EdU incorporation and staining of GFP-positive, transfected cells, and GFP-negative, untransfected cells in the same dish showed a significant inhibition of EdU positivity in the wt HIPK2 and HIPK2K565T expressing cells compared to relative GFP- negative cells. In contrast, the HIPK2-T566P mutant was consistently less efficient in suppressing EdU incorporation (Figure 1C). Overall, these data documented that mutation of the autophosphorylation HIPK2-T566 site in HIPK2 does not affect the nuclear speckle localization of the kinase but might contribute to its proliferationsuppressing activity.

Exogenous HIPK2 overexpression is thought to mirror HIPK2 activity in DDR, while developmental and cytokinesis functions of HIPK2 are better revealed by lossof-function strategies with rescue experiments in HIPK2defective cells that can be obtained only with very low expression of the exogenous kinase [32-34]. Thus, based on our overexpression data, we sought to assess the DDR activity of the endogenous HIPK2-T566P mutant. The CTSC47 cells expressing this mutant and carrying wt p53, as assessed by whole-exome sequencing (Supplementary Table 2), were treated with UV and doxorubicin (Adriamycin - ADR), two strong HIPK2 activators whose activity on HIPK2-defective cells is significantly impaired [35]. As demonstrated by p53-S46 phosphorylation, p21WAF1 expression, caspase 3-cleavage, and reduction of cell viability, U2OS control cells and the CTSC1.1 patientderived cells expressing HIPK2 and p53 in the wild-type form, did respond to both treatments (Figure 2A, left and right panel) [11, 12]. By contrast, the T566P-expressing CTSC47 did respond to ADR treatment but did not to UV-irradiation (Figure 2A, middle panel), suggesting the existence of an agent-specific impairment.

In response to ADR, DYRK2 was also shown to phosphorylate p53-S46 [36]. Thus, we asked whether the preserved response to ADR by the HIPK2-T566P-carrying 
CTSC47 cells might be independent of HIPK2 activity. HIPK2-specific siRNAs were employed to deplete HIPK2 expression in the CTSC47 cells as previously described [37] (Figure 2B). These primary cells grow as spheroids and cannot be efficiently transfected. However, the mild downregulation of HIPK2 was associated to a reduction of p53-S46 phosphorylation in response to ADR (Figure 2C) indicating that the HIPK2-T566P mutant does contribute to ADR-induced p53 activation. Together, the results we obtained on the endogenous HIPK2 suggest a differential
A
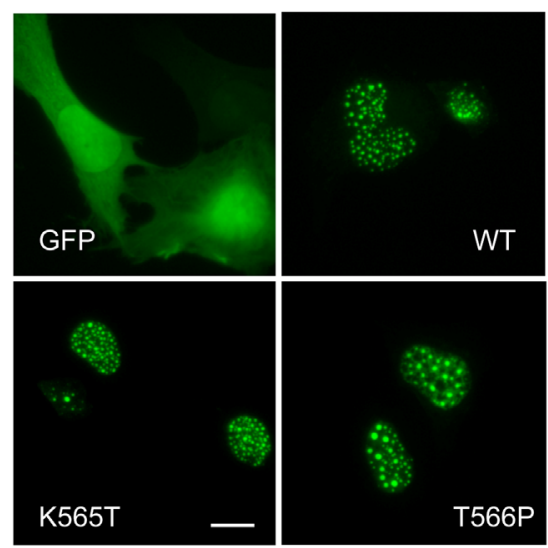

B

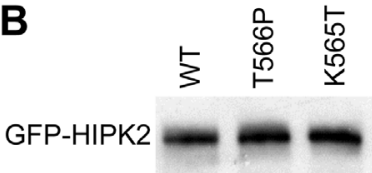

IP: Anti-GFP

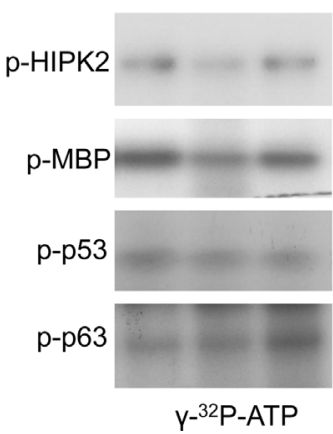

C

GFP-negative cells

口GFP-positive cells

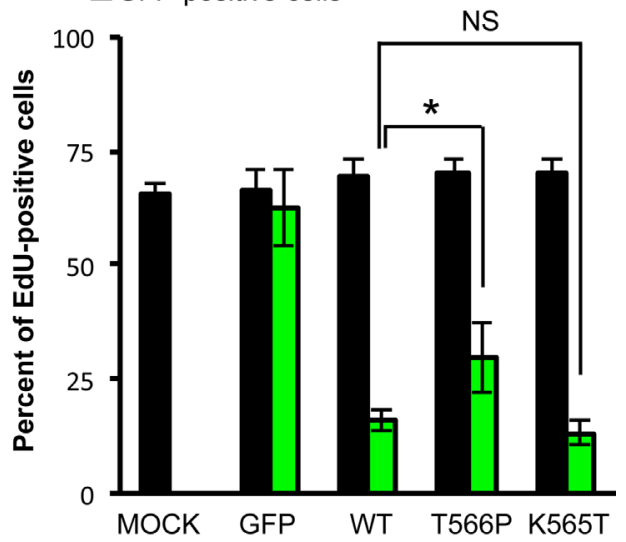

Figure 1: Effect of the T566P mutation on cellular localization, HIPK2 kinase activity, and cell proliferation. A. U2OS cells were transfected with expression vectors for the indicated GFP-tagged HIPK2 derivative. Protein localization was evaluated by direct GFP fluorescence under UV light. U2OS cells transfected with GFP empty vector (GFP) were used as control. Scale bars $10 \mu \mathrm{m}$. B. GFPtagged proteins kinase activity was analyzed by in vitro kinase assay by incubation with the recombinant proteins MBP, p53, and p63, in the presence of $\left[\gamma_{-}{ }^{32} \mathrm{P}\right]$-ATP. Kinase reaction products were resolved by SDS-PAGE and analyzed by autoradiography. Data from one representative experiment out of three is reported. C. U2OS cells were transfected as in (A). EdU-positive cells were detected by fluorescence and counted $24 \mathrm{hrs}$ after transfection. Transfected GFP-positive cells and untransfected GFP-negative cells belong to the same dishes. Data represent the mean \pm Standard Error (SE) of at least three different experiments. ${ }^{*} \mathrm{P}<0.05$; NS $\mathrm{P}>0.05$ by Student $\mathrm{t}$ test.

A

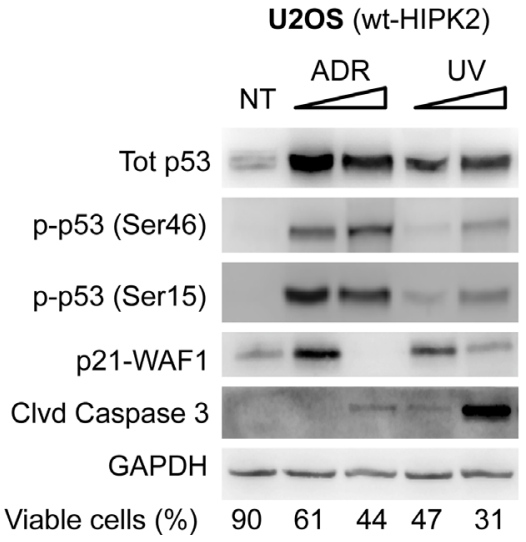

CTSC47 (HIPK2-T566P)

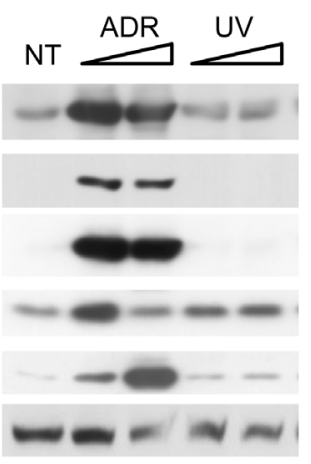

$91 \quad 54 \quad 33 \quad 86 \quad 70$
CTSC1.1 (wt-HIPK2)

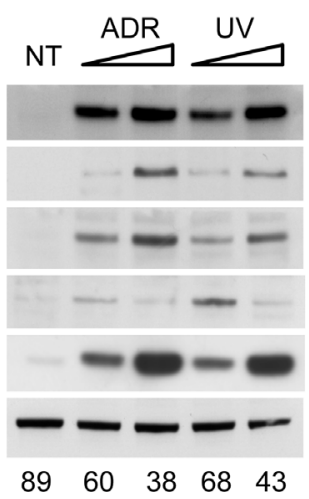

B
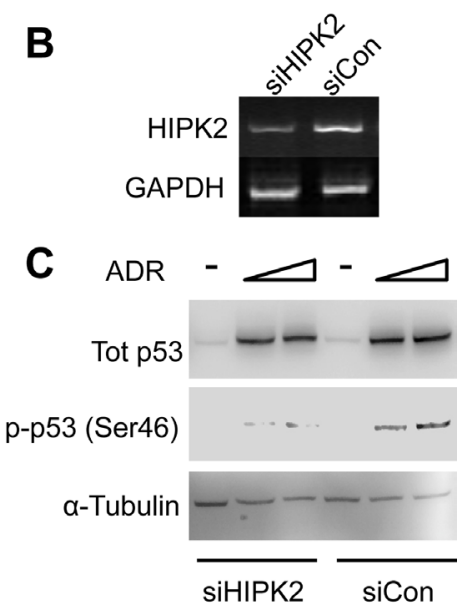

Figure 2: Endogenous HIPK2 (WT vs. T566P) response to ADR and UV. A. WB analysis of the indicated proteins was performed on total cell extracts from wt HIPK2 carrying U2OS and CTSC1.1 cells and HIPK2-T566P carrying CTSC47 cells, prepared 24 hrs after treated with two doses of $\operatorname{ADR}(0.6$ and $3 \mu \mathrm{M})$ and UV $\left(50\right.$ and $\left.150 \mathrm{~J} / \mathrm{m}^{2}\right)$. $\alpha$-Tubulin was used as loading control. Cell viability, determined by Trypan blue exclusion test before cell lysis, is reported as percentage at the bottom of each lane. B. To reduce the expression level of the endogenous HIPK2, CTSC47 cells were transfected with HIPK2-specific siRNAs (siHIPK2) while the UNC siRNA was used as control (siCon). The mRNA expression level was measured by semi-quantitative RT-PCR. GAPDH was used as loading reference. C. Deplete (siHIPK2) and control (siCon) CTSC47 cells were treated with two doses of ADR (0.6 and $3 \mu \mathrm{M})$ for 24 hrs. Total p53 and its phosphorylation at Ser46 were analyzed by WB. $\alpha$-Tubulin was used as a loading control. 
role for the HIPK2-T566 site in cell response to UV and ADR.

Our previous data by liquid chromatography tandem mass spectrometry (LC-MS/MS) on mouse Hipk2 showed that Hipk2-T566 (T559) is an autophosphorylation site and its phosphorylation is lost in the catalytic-impaired K228R (K221R) and Y361F (Y354) mutants [20 and unpublished results]. T566 was not found phosphorylated in the human HIPK 2 by the same analyses [19]. Since negative results by LC-MS/MS do not necessarily indicate the absence of the event and our in silico and functional analyses supported the relevance of the T566P substitution, we developed a T566-phospho-specific Ab (see Materials and Methods) to evaluate the contribution of this phospho-site to UVand ADR-induced DDR. As shown in Figure 3A, the anti-
p-HIPK2 (T566) Ab was demonstrated to immunoreact with human wt HIPK2 while it did not recognize the non-phosphorylatable HIPK2-T566P mutant. In addition, treatment with alkaline phosphatase significantly reduced $\mathrm{Ab}$ immunoreactivity, further supporting the $\mathrm{Ab}$ specificity and confirming the occurrence of phosphorylation at T566 in the kinase. Next, we employed this Ab to assess HIPK2-T566 phosphorylation in UV- and ADR-induced DDR. U2OS cells expressing the GFP-tagged wt HIPK2 were UV-irradiated or treated with ADR. Untreated cells were used as control. As for other HIPK2 S/T sites, we found that HIPK2-T566 was constitutively phosphorylated in the untreated cells (Figure 3B). Interestingly, UVirradiation was associated with dephosphorylation at T566, while ADR-treatment did not modify the T566

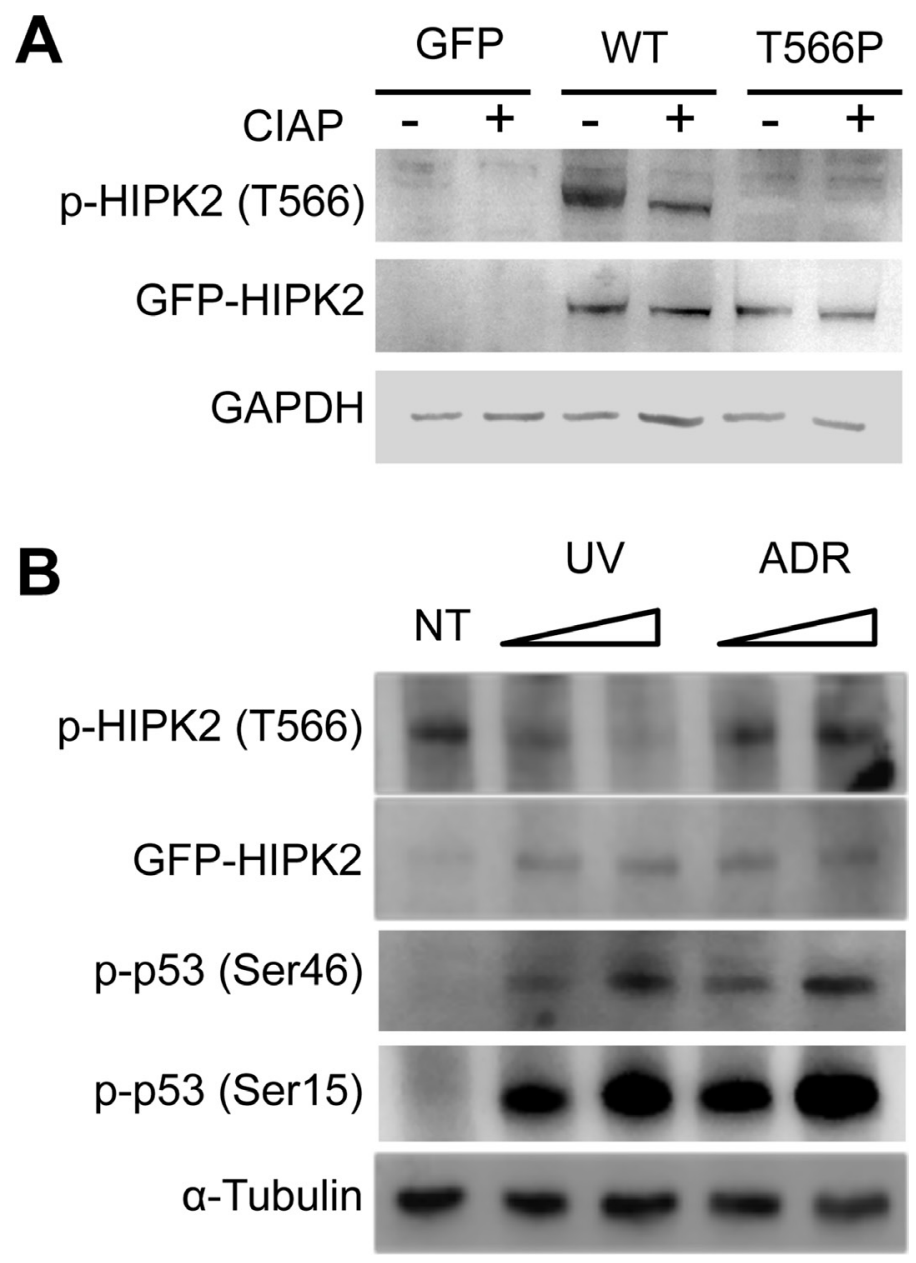

Figure 3: HIPK2-T566 phosphorylation analysis. A. U2OS cells were transfected with the indicated GFP-tagged vectors and total cell extracts analyzed by WB before and after phosphatase (CIAP) treatment. The anti-p-HIPK2 (T566) Ab recognizes the WT protein but not the non-phosphorylatable HIPK2-T566P mutant and gives a strongly reduced signal in the dephosphorylated WT sample. The amount of GFP-tagged HIPK2 proteins (WT and T566P) was detected by anti-GFP Ab. GAPDH was used as loading control. B. U2OS cells were transfected with the GFP-tagged wt HIPK2 and irradiated with UV (50 and $\left.150 \mathrm{~J} / \mathrm{m}^{2}\right)$ or treated with ADR $(0.6$ and $3 \mu \mathrm{M})$. Non-treated (NT) cells were used as control. Total cell extracts were prepared $24 \mathrm{hrs}$ post-treatments and analyzed by WB for the indicated total and phosphorylated proteins. 
phosphorylation status (Figure 3B), though, as expected for a wt HIPK2, both treatments resulted in a comparable p53 phosphorylation at S46, supporting a differential contribution of the HIPK2-T566 phosphorylation status in the UV- and ADR-induced HIPK2 activation.

To verify this differential contribution, U2OS cells were transfected with GFP-tagged wt HIPK2 or the T566P mutant; the GFP-empty vector was transfected as negative control. The three transfected populations were treated with ADR, UV-irradiated, or maintained in non-treated conditions. As expected from the above reported data (Figure 1C), EdU incorporation was reduced by exogenous wt HIPK2 expression and, to a lesser extent, by the T566P mutant (Figure 4, NT bars). ADR-treatment resulted in a comparable, further reduction of EdU incorporation in both wt HIPK2 and HIPK2-T566P expressing cells (Figure 4, ADR bars). In contrast, UV-irradiation further reduced EdU incorporation only in the wt HIPK2 expressing cells, while those expressing the T566P mutant behaved as the GFPcontrol cells (Figure 4, UV bars). These results strongly support the conclusion that the phosphorylation at T566 contributes to UV-mediated reaction of HIPK2 but it is dispensable for the doxorubicin-induced response of the kinase. Taken together, these data show, for the first time, that different genotoxic agents may activate HIPK2 by diversely modulating its autophosphorylation at a single site.

The involvement of HIPK2 in a multitude of biological processes and its participation in many different signaling pathways is made possible by PTMs that increase its functional diversity. In this light, the finding that a specific HIPK2 autophosphorylation site, T566, diversely contributes to UV- and doxorubicin-mediated DDR may not be surprising. However, thus far, HIPK2 activation and function has been indiscriminately studied upon UV, IR or chemotherapeutic drug treatments. For example, HIPK2 autophosphorylation at T880/S882 and Pin1 binding have been studied upon doxorubicin treatment [22]; c-Ablmediated phosphorylation at Y367 upon UV and IR [23]; AMPK $\alpha 2$-mediated phosphorylation at T119, S121, and T1114 upon IR [24]. While generalizations of these results are usually not specifically claimed, we should be aware that the common definition of HIPK2 activation in DDR implies at least diverse phosphorylation states. This should prompt us to expend more effort in developing tools for studying the endogenous protein in both physiological and pathological conditions.

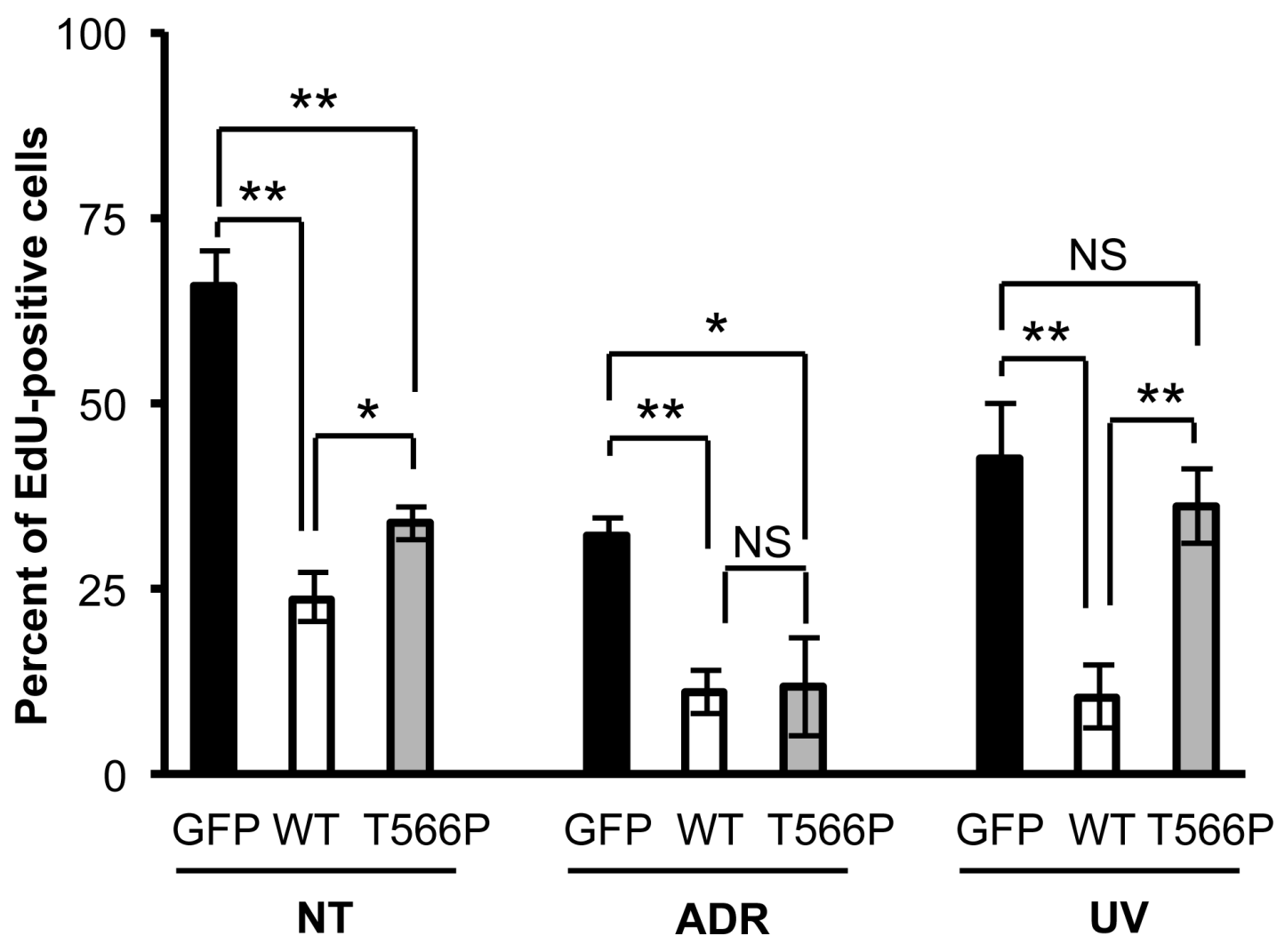

Figure 4: Comparison of the effects induced by UV and ADR treatments on wt HIPK2 and HIPK2-T566P overexpressing cells. U2OS cells were transfected and treated as in Figure 3B (ADR, $0.6 \mu \mathrm{M} ; \mathrm{UV}, 50 \mathrm{~J} / \mathrm{m}^{2}$ ) and analyzed after $48 \mathrm{hrs}$. Inhibition of cell proliferation was assessed by EdU-incorporation and subsequent detection by fluorescence. Data represent the mean $\pm \mathrm{SE}$ of at least three different experiments. ${ }^{*} \mathrm{P}<0.05 ; * * \mathrm{P}<0.001$; NS $\mathrm{P}>0.05$ by Student $\mathrm{t}$ test. 


\section{MATERIALS AND METHODS}

\section{Whole-exome sequencing and data analysis}

Target enrichment was performed using in-solution technology (NimbleGen SeqCap EZ Library v.3.0, Roche), and the resulting target libraries were sequenced by Illumina sequencing technology (HiSeq2000). Raw image files were processed by Illumina basecalling software (CASAVA 1.7) using default parameters. Pairedend reads were aligned to the human genome (UCSC GRCh37/hg19) with the Burrows-Wheeler aligner (BWA v. 0.7.10) [38]. Presumed PCR duplicates were removed using Picard's MarkDuplicates. The Genome Analysis Toolkit (GATK 3.3) [39] was used for realignment of sequences encompassing indels and for base quality recalibration. Somatic single-nucleotide variants were detected using Mutect software v.1.1.6 [40] and small indels were identified through a comparison between indels called in individual C-CSC lines and their matched nontumoral samples by means of the GATK Haplotype Caller algorithm [41], as previously described [42, 43]. The resulting SNVs and small indels were annotated by SnpEff v3.6 [44] and dbNSFP2.8 [45] in terms of functional impact of variants [46, 47]. Variant validation and genotyping were performed by direct sequencing using the ABI BigDye Terminator Sequencing kit (Applied Biosystems) and an ABI3500 capillary sequencer (Applied Biosystems).

\section{Cells culture and RNA interference}

The human osteosarcoma U2OS cells were cultured in DMEM supplemented with 10\% (v/v) FBS and antibiotics (Invitrogen). The patient-derived colon spheroids were kindly provided by Prof R. De Maria and cultured in a serum-free medium supplemented with 20 $\mathrm{ng} / \mathrm{ml} \mathrm{EGF}$ and $10 \mathrm{ng} / \mathrm{ml} \mathrm{FGF-2} \mathrm{(PrePro} \mathrm{-Tech)} \mathrm{[48].} \mathrm{For}$ DDR, subconfluent cells were irradiated with UV-B using a Vilbert Lourmat Irradiator or incubated in the presence of doxorubicin (Adriamycin; Sigma).

RNA interference was obtained by HIPK2-specific Stealth RNAi sequences and Stealth RNAi-negative control (UNC) (Invitrogen), as previously described [37]. Cells were transfected by RNAi-MAX Lipofectamine (Invitrogen) according to manufacturer's instructions and BLOCK-iT Red Fluorescent oligo (Invitrogen) was used to measure RNA transfection efficiency.

\section{RT-PCR}

Total RNA was isolated using the RNeasy mini Kit (Qiagen). cDNA was synthesized using a M-MLTV RTase and amplified with GoTaq DNA polymerase (Promega). The following primers were employed (NCBI RefSeq NM_022740.4):
HIPK2-fw: ggctgaccggegggagtt; HIPK2-rev: ggtcaggccgggcacaaatct.

PCR-amplifications were performed in duplicate on two different RNA preparations.

\section{HIPK2 expression vectors and cell transfection}

The pEGFP-HIPK2-FL vector, encoding for a N-terminal GFP-tagged wild type HIPK2-FL protein [37] was mutagenized by QuickChange II Site-Direct Mutagenesis kit (Agilent) with the following primers:

T566P: cacggtgaaccagagcaaaccccetttcatcac;

K565T: acggtgaaccagagcacaacccctttcatcacg.

The obtained pEGFP-HIPK2-T566P and pEGFP-HIPK2-K565T vectors were validated by direct sequencing and transfected in U2OS cells by electroporation $(0.2 \mathrm{kV}, 950 \mu \mathrm{F})$ using a Gene Pulser (Bio-Rad) or by Lipofectamine (Invitrogen), according to manufacturer's instructions.

\section{In vitro kinase assay}

Recombinant GFP-HIPK2, GFP-K565T and GFPT566P were produced in U2OS cells by transfection with Lipofectamine (Invitrogen). Total cell extracts were prepared $24 \mathrm{hrs}$ post-transfection by incubation for 30 min at $4{ }^{\circ} \mathrm{C}$ in lysis buffer $[50 \mathrm{mM}$ Tris- $\mathrm{HCl}(\mathrm{pH} 7.4)$, $300 \mathrm{mM} \mathrm{NaCl}, 1 \%$ Nonidet P-40, 5mM EDTA, protease and phosphatase inhibitor (Roche)]. When required, to reduce protein phosphorylation, the total cell extracts were incubated at $30^{\circ} \mathrm{C}$ for $30 \mathrm{~min}$ in the presence of 20 $\mathrm{U} / \mathrm{ml}$ calf intestinal alkaline phosphatase (Sigma). After centrifugation, GFP-fusion proteins were purified from supernatant by overnight incubation with anti-GFP Absepharose beads (Abcam) at $4^{\circ} \mathrm{C}$ and used as enzymatic source. Western blot (WB) analysis with a different antiGFP Ab (mouse monoclonal anti-GFP Ab, Roche) was employed to quantify purified proteins. For kinase assay, recombinant proteins were incubated with recombinant $\mathrm{p} 53$, p63, and $\mathrm{MBP}$ for $30 \mathrm{~min}$ at $30^{\circ} \mathrm{C}$ in a kinase buffer in the presence of $\left[\gamma^{32} \mathrm{P}\right]$-ATP, as described [15]. The phosphorylated substrates were resolved on precast NuPAGE $4-12 \%$ gels (Thermo Fisher Scientific) and analyzed by autoradiography.

\section{Western blotting and antibodies}

A rabbit polyclonal $\mathrm{Ab}$ recognizing the phosphorylated HIPK2-T566 site, anti-p-HIPK2 (Thr566) $\mathrm{Ab}$ was raised against a phospho-peptide representing the human HIPK2 region surrounding T566 and affinity purified with the immunizing phosphorylated peptide after negative absorption with the non-phosphorylated peptide. Peptide design, Ab production and purification were all performed by the custom antibody service of Thermofisher. 
Total cell extracts were prepared, separated, transferred onto nitrocellulose membrane, and immunodecorated as described [37]. The following, additional Abs were employed: anti-GFP (mouse monoclonals, clones 7.1 and 13.1 - Roche), anti-p53 (mouse monoclonal: clone DO-1 - Santa Cruz Biotechnology), anti-p-p53(Ser46) (rabbit polyclonal - Santa Cruz Biotechnology), anti-p21 (mouse polyclonal - Santa Cruz Biotechnology), anti-p-p53(Ser15) (rabbit polyclonal - Cell Signaling Technology), anti-cleaved caspase-3 (rabbit polyclonal - Cell Signaling Technology), anti- $\alpha-$ tubulin (mouse monoclonal, clone TU-01 - Immunological Science), anti-GAPDH (mouse monoclonal, clone 6C5 - Santa Cruz Biotechnology). Following incubation for 1 $\mathrm{hr}$ at room temperature with secondary antibodies, antiHRP-conjugated goat-anti-mouse and goat-anti-rabbit (Bio-Rad Laboratories), bound Abs were reviled by ECLWB Detection System (GE Healthcare) and analyzed by chemiluminescence imaging system (UVITEC Cambridge).

\section{EdU incorporation and detection}

Cells were incubated in the presence of $10 \mu \mathrm{M}$ EdU labeling solution for $3 \mathrm{hrs}$, fixed in $2 \%$ formaldehyde, permeabilized with $0.25 \%$ TritonX 100 , blocked with $5 \%$ BSA an developed according to manufacturing instructions (Click-iT® EdU imaging Kit, ThermoFisher). Nuclei were counterstained with $1 \mathrm{X}$ Hoechst ${ }^{\circledR}$ 33342. At least 500 cells per sample were counted. Fluorescent signals were recorded by Olympus BX53 microscope (Olympus Life Science) and images were captured with a ProgRes MFCOOL camera (Jenoptik) at a magnification of 40X.

\section{Statistical analyses}

For comparison between two independent groups, the Student's t-test was used.

\section{CONFLICTS OF INTEREST}

The authors declare no conflicts of interest.

\section{GRANT SUPPORT}

This work was supported by the Italian Association for Cancer Research (AIRC) with a "5 per mille" grant (9979) to S.S. and M.T.

\section{REFERENCES}

1. Calzado MA, De La Vega L, Munoz E, Schmitz ML. From top to bottom: the two faces of HIPK2 for regulation of the hypoxic response. Cell Cycle. 2009; 8:1659-1664.
2. D'Orazi G, Rinaldo C, Soddu S. Updates on HIPK2: a resourceful oncosuppressor for clearing cancer. J Exp Clin Cancer Res. 2012; 31:1-8.

3. Hofmann TG, Glas C, Bitomsky N. HIPK2: A tumour suppressor that controls DNA damage-induced cell fate and cytokinesis. Bioessays. 2013; 35:55-64.

4. Wook Choi D, Yong Choi C. HIPK2 modification code for cell death and survival. Mol Cell Oncol. 2014; 1:e955999.

5. de la Vega L, Fröbius K, Moreno R, Calzado MA, Geng $\mathrm{H}$, Schmitz ML. Control of nuclear HIPK2 localization and function by a SUMO interaction motif. Biochim Biophys Acta. 2011; 13:283-297.

6. Winter M, Sombroek D, Dauth I, Moehlenbrink J, Scheuermann K, Crone J, Hofmann TG. Control of HIPK2 stability by ubiquitin ligase Siah-1 and checkpoint kinases ATM and ATR. Nat Cell Biol. 2008; 10:812-824.

7. Rinaldo C, Prodosmo A, Mancini F, Iacovelli S, Sacchi A, Moretti F, Soddu S. MDM2-regulated degradation of HIPK2 prevents p53Ser46 phosphorylation and DNA damage-induced apoptosis. Mol Cell. 2007; 25:739-750.

8. Choi DW, Seo YM, Kim EA, Sung KS, Ahn JW, Park SJ, Lee SR, Choi CY. Ubiquitination and degradation of homeodomain-interacting protein kinase 2 by WD40 repeat/SOCS box protein WSB-1. J Biol Chem. 2008; 283:4682-4689.

9. Sombroek D HT. How cells switch HIPK2 on and off. Cell Death Differ. 2009; 16:187-194.

10. Kim SY, Choi DW, Kim EA, Choi CY. Stabilization of HIPK2 by escape from proteasomal degradation mediated by the E3 ubiquitin ligase Siah1. Cancer Lett. 2009; 279:177-184.

11. D'Orazi G, Cecchinelli B, Bruno T, Manni I, Higashimoto Y, Saito S, Gostissa M, Coen S, Marchetti A, Del Sal G, Piaggio G, Fanciulli M, Appella E, Soddu S. Homeodomaininteracting protein kinase-2 phosphorylates p53 at Ser 46 and mediates apoptosis. Nat Cell Biol. 2002; 4:11-19.

12. Hofmann TG, Möller A, Sirma H, Zentgraf H, Taya Y, Dröge W, Will H, Schmitz ML. Regulation of p53 activity by its interaction with homeodomain-interacting protein kinase-2. Nat Cell Biol. 2002; 4:1-10.

13. Zhang Q, Yoshimatsu Y, Hildebrand J, Frisch SM, Goodman RH. Cell Homeodomain interacting protein kinase 2 promotes apoptosis by downregulating the transcriptional corepressor CtBP. Cell. 2003; 115:177-186.

14. Dauth I, Krüger J, Hofmann TG. Homeodomain-interacting protein kinase 2 is the ionizing radiation-activated p53 serine 46 kinase and is regulated by ATM. Cancer Res. 2007; 67:2274-2279.

15. Lazzari C, Prodosmo A, Siepi F, Rinaldo C, Galli F, Gentileschi M, Bartolazzi A, Costanzo A, Sacchi A, Guerrini L, Soddu S. HIPK2 phosphorylates $\Delta$ Np63 $\alpha$ and promotes its degradation in response to DNA damage. Oncogene. 2011; 30:4802-4813. 
16. Gresko E, Roscic A, Ritterhoff S, Vichalkovski A, del Sal G, Schmitz ML. Autoregulatory control of the p53 response by caspase-mediated processing of HIPK2. EMBO J. 2006; 25:1883-1894.

17. de la Vega L, Grishina I, Moreno R, Krüger M, Braun T, Schmitz ML. A redox-regulated SUMO/acetylation switch of HIPK2 controls the survival threshold to oxidative stress. Mol Cell. 2012; 46:472-483.

18. Saul VV, Schmitz ML. Post-translational modifications regulate HIPK2, a driver of proliferative diseases. J Mol Med (Berl). 2013; 91:1051-1058.

19. Saul VV, de la Vega L, Milanovic M, Krüger M, Braun T, Fritz-Wolf K, Becker K, Schmitz ML. HIPK2 kinase activity depends on cis-autophosphorylation of its activation loop. J Mol Cell Biol. 2013; 5:27-38.

20. Siepi F, Gatti V, Camerini S, Crescenzi M, Soddu S. HIPK2 catalytic activity and subcellular localization are regulated by activation-loop Y354 autophosphorylation. Biochim Biophys Acta. 2013; 1833:1443-1453.

21. van der Laden J, Soppa U, Becker W. Effect of tyrosine autophosphorylation on catalytic activity and subcellular localisation of homeodomain-interacting protein kinases (HIPK). Cell Commun Signal. 2015; 13:1-11.

22. Bitomsky N, Conrad E, Moritz C, Polonio-Vallon T, Sombroek D, Schultheiss K, Glas C, Greiner V, Herbel C, Mantovani F, del Sal G, Peri F, Hofmann TG. Autophosphorylation and Pin1 binding coordinate DNA damage-induced HIPK2 activation and cell death. Proc Natl Acad Sci U S A. 2013; 110:E4203-E4212.

23. Reuven N, Adler J, Porat Z, Polonio-Vallon T, Hofmann TG, Shaul Y. The Tyrosine Kinase c-Abl Promotes Homeodomain-interacting Protein Kinase 2 (HIPK2) Accumulation and Activation in Response to DNA Damage. J Biol Chem. 2015; 290:16478-16488.

24. Choi DW, Na W, Kabir MH, Yi E, Kwon S, Yeom J, Ahn JW, Choi HH, Lee Y, Seo KW, Shin MK, Park SH, Yoo HY, Isono K, Koseki H, Kim ST, Lee C, Kwon YK, Choi CY. WIP1, a homeostatic regulator of the DNA damage response, is targeted by HIPK2 for phosphorylation and degradation. Mol Cell. 2013; 51:374-385.

25. Lee S, Shang Y, Redmond SA, Urisman A, Tang AA, Li $\mathrm{KH}$, Burlingame AL, Pak RA, Jovičić A, Gitler AD, Wang J, Gray NS, Seeley WW, Siddique T, Bigio EH, Lee VM, Trojanowski JQ, Chan JR, Huang EJ. Activation of HIPK2 Promotes ER Stress-Mediated Neurodegeneration in Amyotrophic Lateral Sclerosis. Neuron. 2016; 91:41-55.

26. Kwon MJ, Min SK, Seo J, Kim DH, Sung CO, Lim MS, Cho J, Park HR. HIPK2 expression in progression of cutaneous epithelial neoplasm. Int J Dermatol. 2015; 54:347-354.

27. Nardinocchi L, Puca R, Givol D, D'Orazi G. HIPK2-a therapeutical target to be (re)activated for tumor suppression: role in p53 activation and HIF-1 $\alpha$ inhibition. Cell Cycle. 2010; 9:1270-1275.
28. Ying Fan, Niansong Wang, Peter Chuang, John C. He. Role of HIPK2 in kidney fibrosis. Kidney International Supplements. 2014; 4:97-101.

29. Li XL, Arai Y, Harada H, Shima Y, Yoshida H, Rokudai S, Aikawa Y, Kimura A, Kitabayashi I. Mutations of the HIPK2 gene in acute myeloid leukemia and myelodysplastic syndrome impair AML1- and p53-mediated transcription. Oncogene. 2007; 26:7231-7239.

30. De Angelis ML, Zeuner A, Policicchio E, Russo G, Bruselles A, Signore M, Vitale S, De Luca G, Pilozzi E, Boe A, Stassi G, Ricci-Vitiani L, Amoreo CA, et al. Cancer Stem Cell-Based Models of Colorectal Cancer Reveal Molecular Determinants of Therapy Resistance. Stem Cells Transl Med. 2016; 5:511-523.

31. Kircher M, Witten DM, Jain P, O'Roak BJ, Cooper GM, Shendure J. A general framework for estimating the relative pathogenicity of human genetic variants. Nat Genet. 2014; 46:310-315.

32. Wiggins AK, Wei G, Doxakis E, Wong C, Tang AA, Zang K, Luo EJ, Neve RL, Reichardt LF, Huang EJ. Interaction of Brn3a and HIPK2 mediates transcriptional repression of sensory neuron survival. J Cell Biol. 2004; 167:257-267.

33. Zhang J, Pho V, Bonasera SJ, Holtzman J, Tang AT, Hellmuth J, Tang S, Janak PH, Tecott LH, Huang EJ. Essential function of HIPK2 in TGFbeta-dependent survival of midbrain dopamine neurons. Nat Neurosci. 2007; 10:77-96.

34. Rinaldo C, Moncada A, Gradi A, Ciuffini L, D'Eliseo D, Siepi F, Prodosmo A, Giorgi A, Pierantoni GM, Trapasso F, Guarguaglini G, Bartolazzi A, Cundari E, Schininà ME, Fusco A, Soddu S. HIPK2 controls cytokinesis and prevents tetraploidization by phosphorylating histone $\mathrm{H} 2 \mathrm{~B}$ at the midbody. Mol Cell. 2012; 47:87-98.

35. Puca R, Nardinocchi L, Givol D, D'Orazi G. Regulation of p53 activity by HIPK2: molecular mechanisms and therapeutical implications in human cancer cells. Oncogene. 2010; 29:4378-4387.

36. Taira N, Nihira K, Yamaguchi T, Miki Y, Yoshida K. DYRK2 is targeted to the nucleus and controls p53 via Ser46 phosphorylation in the apoptotic response to DNA damage. Mol Cell. 2007; 25:725-738.

37. Di Rocco G, Verdina A, Gatti V, Virdia I, Toietta G, Todaro M, Stassi G, Soddu S. Apoptosis induced by a HIPK2 fulllength-specific siRNA is due to off-target effects rather than prevalence of HIPK2- $\Delta \mathrm{e} 8$ isoform. Oncotarget. 2016; 7:1675-1686. doi: 10.18632/oncotarget.6423.

38. Li H, Durbin R. Fast and accurate short read alignment with Burrows-Wheeler transform. Bioinformatics. 2009; 25:1754-1760.

39. McKenna A, Hanna M, Banks E, Sivachenko A, Cibulskis K, Kernytsky A, Garimella K, Altshuler D, Gabriel S, Daly M, DePristo MA. The Genome Analysis Toolkit: a MapReduce framework for analyzing next-generation DNA sequencing data. Genome Res. 2010; 20:1297-1303. 
40. Cibulskis K, Lawrence MS, Carter SL, Sivachenko A, Jaffe D, Sougnez C, Gabriel S, Meyerson M, Lander ES, Getz G. Sensitive detection of somatic point mutations in impure and heterogeneous cancer samples. Nat Biotechnol. 2013; 31:213-219.

41. DePristo MA, Banks E, Poplin R, Garimella KV, Maguire JR, Hartl C, Philippakis AA, del Angel G, Rivas MA, Hanna M, McKenna A, Fennell TJ, Kernytsky AM, et al. A framework for variation discovery and genotyping using next-generation DNA sequencing data. Nat Genet. 2011; 43:491-498.

42. Cordeddu V, Redeker B, Stellacci E, Jongejan A, Fragale A, Bradley TE, Anselmi M, Ciolfi A, Cecchetti S, Muto V, Bernardini L, Azage M, Carvalho DR, et al. Mutations in ZBTB20 cause Primrose syndrome. Nat Genet. 2014; 46:815-817.

43. Niceta M, Stellacci E, Gripp KW, Zampino G, Kousi M, Anselmi M, Traversa A, Ciolfi A, Stabley D, Bruselles A, et al. Mutations impairing GSK3-mediated MAF phosphorylation cause cataract, deafness, intellectual disability, seizures, and a Down syndrome- like Facies. Am J Hum Genet. 2015; 96:816-825.

44. Cingolani P, Platts A, Wang le L, Coon M, Nguyen T, Wang L, Land SJ, Lu X, Ruden DM. A program for annotating and predicting the effects of single nucleotide polymorphisms, SnpEff: SNPs in the genome of Drosophila melanogaster strain w1118; iso-2; iso-3. Fly (Austin). 2012; 6:80-92.

45. Liu X, Jian X, Boerwinkle E. dbNSFP v2.0: a database of human non-synonymous SNVs and their functional predictions and annotations. Hum Mutat. 2013; 34:E2393-402.

46. Kortüm F, Caputo V, Bauer CK, Stella L, Ciolfi A, Alawi M, Bocchinfuso G, Flex E, Paolacci S, Dentici ML, Grammatico P, Korenke GC, Leuzzi V, et al. Mutations in KCNH1 and ATP6V1B2 cause Zimmermann-Laband syndrome. Nat Genet. 2015; 47:661-667.

47. Flex E, Niceta M, Cecchetti S, Thiffault I, Au MG, Capuano A, Piermarin E, Ivanova AA, Francis JW, Chillemi G, Chandramouli B, Carpentieri G, Haaxma CA, et al. Biallelic Mutations in TBCD, Encoding the Tubulin Folding Cofactor D, Perturb Microtubule Dynamics and Cause Early-Onset Encephalopathy. Am J Hum Genet. 2016; 99:1-12.

48. Ricci-Vitiani L, Lombardi DG, Pilozzi E, Biffoni M, Todaro M, Peschle C, De Maria R. Identification and expansion of human colon-cancer-initiating cells. Nature. 2007; 445:111-115.

49. Polonio-Vallon T, Kirkpatrick J, Krijgsveld J, Hofmann TG. Src kinase modulates the apoptotic p53 pathway by altering HIPK2 localization. Cell Cycle. 2014; 13:115-125.

50. DeNardo BD, Holloway MP, Ji Q, Nguyen KT, Cheng Y, Valentine MB, Salomon A, Altura RA. Quantitative phosphoproteomic analysis identifies activation of the RET and IGF-1R/IRsignaling pathways in neuroblastoma. PLoS One. 2013; 8:e82513.
51. Bai Y, Li J, Fang B, Edwards A, Zhang G, Bui M, Eschrich S, Altiok S, Koomen J, Haura EB. Phosphoproteomics identifies driver tyrosine kinases in sarcoma cell lines and tumors. Cancer Res. 2012; 72:2501-2511.

52. Bian Y, Song C, Cheng K, Dong M, Wang F, Huang J, Sun D, Wang L, Ye M, Zou H. An enzyme assisted RP-RPLC approach for in-depth analysis of human liverphosphoproteome. J Proteomics. 2014; 96:253-262

53. Wu X, Tian L, Li J, Zhang Y, Han V, Li Y, Xu X, Li H, Chen X, Chen J, Jin W, Xie Y, Han J, Zhong CQ. Investigation of receptor interacting protein (RIP3)-dependent protein phosphorylationby quantitative phosphoproteomics. Mol Cell Proteomics. 2012; 11:1640-1651.

54. Klammer M, Kaminski M, Zedler A, Oppermann F, Blencke S, Marx S, Müller S, Tebbe A, Godl K, Schaab C. Phosphosignature predicts dasatinib response in non-small cell lung cancer. Mol Cell Proteomics. 2012; 11:651-668.

55. Goswami T, Li X, Smith AM, Luderowski EM, Vincent JJ, Rush J, Ballif BA. Comparative phosphoproteomic analysis of neonatal and adult murine brain. Proteomics. 2012; 12:2185-2189.

56. Yi T, Zhai B, Yu Y, Kiyotsugu Y, Raschle T, Etzkorn M, Seo HC, Nagiec M, Luna RE, Reinherz EL, Blenis J, Gygi SP, Wagner G. Quantitative phosphoproteomic analysis reveals system-wide signaling pathwaysdownstream of SDF-1/ CXCR4 in breast cancer stem cells. Proc Natl Acad Sci U S A. 2014; 111:E2182-E2190.

57. Helou YA, Nguyen V, Beik SP, Salomon AR. ERK positive feedback regulates a widespread network of tyrosine phosphorylation sitesacross canonical $\mathrm{T}$ cell signaling and actin cytoskeletal proteins in Jurkat T cells. PLoS One. 2013; 8:e69641.

58. Humphrey SJ, Yang G, Yang P, Fazakerley DJ, Stöckli J, Yang JY, James DE. Dynamic adipocyte phosphoproteome reveals that Akt directly regulates mTORC2. Cell Metab. 2013; 17:1009-1020.

59. Huttlin EL, Jedrychowski MP, Elias JE, Goswami T, Rad R, Beausoleil SA, Villén J, Haas W, Sowa ME, Gygi SP. A tissue-specific atlas of mouse protein phosphorylation and expression. Cell. 2010; 143:1174-1189.

60. Stuart SA, Houel S, Lee T, Wang N, Old WM, Ahn NG. A Phosphoproteomic Comparison of B-RAFV600E and MKK1/2 Inhibitors in Melanoma Cells. Mol Cell Proteomics. 2015; 14:1599-1615.

61. Mertins P, Qiao JW, Patel J, Udeshi ND, Clauser KR, Mani DR, Burgess MW, Gillette MA, Jaffe JD, Carr SA. Integrated proteomic analysis of post-translational modifications by serial enrichment. Nat Methods. 2013; 10:634-637.

62. Oppermann FS, Gnad F, Olsen JV, Hornberger R, Greff Z, Kéri G, Mann M, Daub H. Large-scale proteomics analysis of the human kinome. Mol Cell Proteomics. 2009; 8:1751-1764. 